06

\title{
Эффрект совместного влияния малых добавок углеродных наночастиц различной морфлогии на механические характеристики сшитых полиуретанов при статических и динамических нагрузках
}

\author{
(C) Г.В. Гаркушин, ${ }^{1,2}$ C.В. Разоренов, ${ }^{1,3}$ А.Е. Тарасов, ${ }^{1}$ Д.В. Анохин, ${ }^{1,3,4}$ Э.Р. Бадамшина ${ }^{1,4}$ \\ ${ }^{1}$ Институт проблем химической фризики РАН, \\ 142432 Черноголовка, Россия \\ ${ }^{2}$ Национальный исследовательский Томский государственный университет, \\ 634050 Томск, Россия \\ ${ }^{3}$ Московский государственный университет им. М.В. Ломоносова, \\ 119991 Москва, Россия \\ ${ }^{4}$ Московский фризико-технический институт, \\ 141701 Долгопрудный, Московская обл., Россия \\ e-mail: garkushin@ficp.ac.ru
}

Поступило в Редакцию 15 октября 2018г

В окончательной редакции 15 октября 2018 r.

Принято к публикации 19 ноября 2018г.

Исследовано влияние малых добавок фуллерена, оксида графена и их сочетаний в соотношении 85/15 на структуру и механические свойства сшитых полиуретанов при статических и динамических нагрузках. Структура нанокомпозитов изучена методами рентгеноструктурного анализа и сканирующей электронной микроскопии. Показано, что наличие углеродных наночастиц в композите приводит к снижению его прочности как при статических нагрузках, так и при ударно-волновом нагружении. Синергетический эффект смеси углеродных наночастиц проявляется в увеличении модуля упругости в 1.25 раза по сравнению с исходным полимером.

DOI: 10.21883/JTF.2019.06.47641.358-18

\section{Введение}

В настоящее время уделяется большое внимание использованию углеродных наночастиц (УНЧ) различной морфологии для создания композиционных материалов, в частности, полимерных композиционных материалов, с улучшенными по сравнению с исходными полимерами физико-механическими, электро- теплопроводящими и другими свойствами. Общеизвестным фактом является то, что положительный эффект влияния УНЧ в огромной степени зависит от их равномерного распределения в полимерной матрице, для чего необходимо преодолеть склонность УНЧ к агрегации из-за высокой поверхностной энергии. Одним из путей решения этой проблемы может быть использование сочетаний двух типов наночастиц, например, углеродных нанотрубок (УНТ) и графеновых нанопластин (ГНП) [1-6], ГНП и наноалмазов [5] и др. Это положительным образом сказывается на механических свойствах эпоксидных нанокомпозитов [1,2,7], поливинилацетатных волокон $[3,8]$, полидиметилсилоксана [4], поливинилового спирта [5], натурального каучука [9] и протеинового композита, стабилизированного нанофибриллированной целлюлозой [10]. Улучшение механических свойств за счет синергетического эффекта при использовании многостенных УНТ и графеновых наночастиц наблюдали и в случае эпоксидных углепластиков [11]. Авторы ряда работ $[1,2,4,6]$ объясняют более равномерное распре- деление нанодобавок (от 0.1 до $1 \mathrm{wt} . \%$ ) в полимерах тем, что разные типы углеродных наночастиц, проникая в межслоевое пространство друг друга, препятствуют процессам агрегации.

В работах $[6,12]$ представлены результаты исследований наномодифицированных одновременно двумя типами углеродных наночастиц полиуретанов (ПУ), одних из наиболее востребованных видов полимеров, широко используемых в качестве лакокрасочных и защитных покрытий, адгезивов, герметиков, изоляторов, прокладок, деталей одежды и обуви, имплантатов и пр. Так, в работе [6] описано изготовление ИК-триггерных приводов с использованием термопластичных ПУ, наномодифицированных смесью сульфированных нанотрубок и восстановленного оксида графита. Улучшение физикомеханических свойств продемонстрировано в [12] для термопластичных ПУ, содержащих графеновые нанопластины и углеродные нанотрубки в соотношении 6:4, по сравнению с нанокомпозитами, содержащими каждый из углеродных нанонаполнителей по отдельности. Этот эффект связан с тем, что нанокомпозит, содержащий смесь указанных УНЧ, как установлено, является более гомогенным и характеризуется меньшим размером агрегатов. Авторы работ $[1,7]$ предположили, что комбинация УНТ и ГНП способствует формированию эффективной трехмерной структуры, характеризующейся большей площадью взаимодействия между нанона- 
полнителями и полимерной матрицей, чем в случае отдельного использования УНТ или ГНП.

Сочетание фуллерена, улучшающего, как известно, свойства ПУ по сравнению с ненаполненными образцами $[13,14]$, с другими видами УНЧ также приводит к проявлению синергетического эффекта в плане улучшения физико-механических, электрических и физикохимических характеристик нанокомпозитов [15]. В частности, пьезоэлектрические полые нанопроволоки и ламели с вытянутыми цепями были получены из поливинилиденфторида, модифицированного фуллереном и многостенными УНТ [15]. При этом не удалось обнаружить публикаций, в которых демонстрируется синергетический эффект от введения фуллерена и ГНП в ПУ эластомеры. Отметим, что в последнее время исследователи проявляют большой интерес к окисленным формам графенов (ОГ) [16-18]. Это вполне объяснимо, так как ОГ, которые являются в большинстве случаев сырьем для получения ГНП, содержат на поверхности достаточное количество высокореакционных функциональных групп. После восстановления ОГ до ГНП, последние, чаще всего, подвергают функционализации для повышения эффективности взаимодействия с матрицей. Использование ОГ в качестве модификаторов полимерных матриц вместо ГНП устраняет сразу две трудоемкие и малопроизводительные операции - восстановление ОГ до ГНП и последующую их функционализацию.

Целью настоящей работы является исследование совместного влияния фуллерена и оксида графена на физико-механические свойства сшитого полиуретанового эластомера при статических, динамических нагрузках и ударно-волновых испытаниях.

\section{1. Экспериментальная часть}

\section{1. Методика синтеза сшитого полиуретанмочевинного эластомера (СПУМЭ)}

Синтез полимерных образцов для механических испытаний при разной скорости деформирования осуществлялся следующим образом. В реактор, снабженный рубашкой охлаждения и механической мешалкой, загружали форполимер на основе политетрагидрофурана и 2,4-толуилендиизоцианата (Adiprene L100) и $\varepsilon$-капролактам (марка „А“, сорт „Высший“, ГОСТ 7850-86), предварительно высушенный на роторном испарителе $\left(10 \mathrm{~Pa}, 60^{\circ} \mathrm{C}\right)$ в течение $2 \mathrm{~h}$ в количестве, необходимом для блокирования всех изоцианатных групп Adiprene L100. Реакционная смесь при перемешивании нагревалась до $90^{\circ} \mathrm{C}$ и выдерживалась при этой температуpe в течение $6 \mathrm{~h}$. Процедура блокирования позволяет использовать смесь форполимера с отвердителем при нормальных условиях длительное время, не опасаясь образования сшитого полимера [19]. К блокированному Адипрену добавляли расчетное количество отвердителя (Ethacure 100 - смесь 3.5-диэтилтолуилен-2.4-диамина и 3.5-диэтилтолуилен-2.6-диамина без предварительной очистки), перемешивали и добавляли различные количества УНЧ в виде дисперсии в химически чистом толуоле. В качестве углеродных добавок использовали фуллерен С60 чистотой 99.8\% (ООО „БИТ“, Нижний Новгород) и оксид графена (ОГ), полученный модифицированным методом Хаммерса [20]. По данным ИК-спектроскопии, элементного анализа и термогравиметрии, сопряженной с квадрупольной масс-спектрометрией, ОГ содержит в своем составе около 35 wt.\% функциональных групп: простых эфирных, сложноэфирных, метильных, метиленовых и гидроксильных. Оксид графена был предварительно сублимирован добавлением бензола и испарением его в твердой фазе. Дисперсия ОГ получена путем добавления толуола в сублимированный ОГ и обработкой на ультразвуковом диспергаторе (частота $22 \mathrm{MHz}$, мощность генератора УЗ $200 \mathrm{~W}$ ) в течение $1 \mathrm{~h}$. Температура среды в процессе обработки ультразвуком оставалась в пределах 55-60 С. Аналогично была диспергирована смесь ОГ с фуллереном в соотношении $15 / 85$. Толуол откачивали при перемешивании, нагревании до $70^{\circ} \mathrm{C}$ и вакуумировании в течение $1 \mathrm{~h}$, после чего реакционную смесь с УНЧ заливали в разогретую до температуры отверждения форму и отверждали в течение $6 \mathrm{~h}$ при $160^{\circ} \mathrm{C}$. Таким образом были получены пластины сшитого полиуретана с добавками наноуглеродных порошков различной морфологии, необходимых для механических испытаний, размеров и толщины.

\section{2. Методики механических испытаний полученных полимеров при статических и динамических нагрузках}

Лопатки для статических испытаний вырезали из полученных отвержденных пленок СПУМЭ толщиной $3 \mathrm{~mm}$ по ГОСТ Р 54553-2011. Физико-механические испытания лопаток на разрыв проводились (при одинаковых условиях хранения образов) на разрывной машине Zwick Z010 TC-FR010TH, скорость деформирования $100 \mathrm{~mm} / \mathrm{min}$, относительная ошибка измерения физикомеханический характеристик не превышала 3\%.

Динамический механический анализ СПУМЭ осуществляли с помощью прибора DMA 242 C (фирмы Netzsch-Gerätebau GmbH, Германия) в режиме двухплечевого изгиба на плоских образцах толщиной $\sim 1.8 \mathrm{~mm}$, шириной $3.7 \mathrm{~mm}$ и рабочей длиной $2 \times 5 \mathrm{~mm}$ при непрерывном сканировании температуры от -100 до $100^{\circ} \mathrm{C}$ со скоростью $2 \%$ min в атмосфере воздуха. К образцам прикладывалась синусоидальная осциллирующая сила, позволяющая развить амплитуду деформации $30 \mu \mathrm{m}$, при фиксированной частоте $1 \mathrm{~Hz}$. Температура стеклования образцов определялась по значению ординаты максимума пика в области $\alpha$-релаксации на зависимости тангенса угла потерь от температуры.

Эксперименты по малоугловой дифракции были проведены на линии ID02 Европейского центра синхротронного излучения (Гренобль, Франция). Картины рас- 
сеяния были измерены в геометрии „на просвет“ при помощи детектора Frelon 2k, расположенного на расстоянии $1.5 \mathrm{~m}$ от образца. Длина волны рентгеновского излучения составляла $\lambda=0.1 \mathrm{~nm}$. Величина модуля вектора рассеяния $q=4 \pi \sin \theta / \lambda$, где $\theta-$ угол рассеяния, калибровалась с использованием нескольких порядков бегената серебра. Одномерные профили рассеяния были получены путем радиального интегрирования двумерных дифрактограмм после коррекции на интенсивность падающего пучка и поглощение образца.

Электронные микрофотографии внутренней структуры образцов были получены на сканирующем электронном микроскопе высокого разрешения Supra 50VP c системой микроанализа INCA Energy ${ }^{+}$, диапазон ускоряющих напряжений 100-30000 V, ускоряющее напряжение $80 \mathrm{kV}$. Для проявления неоднородностей структуры поверхность скола образца подвергали травлению в кислородной плазме и напыляли углерод, на полученную углеродную реплику напыляли слой платины под углом $30^{\circ}$.

Ударно-волновые испытания образцов СПУМЭ с различным содержанием УНЧ осуществляли с помощью специальных взрывных устройств [21]. Испытуемые образцы вырезались из широкой части лопаток после их тестов на разрывной машине. Таким образом, и статические и динамические измерения были выполнены на одних и тех же синтезированных образцах. Толщины образцов соответствовали толщине лопаток и составляли 2-1.8 mm. Так как приготовленные тонкие образцы полимера были гибкими и полупрозрачными, в экспериментальной сборке для жесткости они располагались на плоском 2-mm алюминиевом экране, а на тыльную поверхность образца наклеивалась алюминиевая фольга толщиной $10 \mu \mathrm{m} \mathrm{c} \mathrm{целью} \mathrm{обеспечения} \mathrm{отражения}$ лазерного зондирующего излучения в экспериментах с лазерным интерферометром. Импульс сжатия (плоская ударная волна) амплитудой $1.35-1.5 \mathrm{GPa}$ вводился в образец через экран при соударении последнего с алюминиевой пластиной толщиной $0.4 \mathrm{~mm}$, разогнанной до скорости $630 \pm 30 \mathrm{~m} / \mathrm{s}$ с помощью специальной сборки для метания тонких пластин ударной волной [21]. При отражении ударной волны от свободной тыльной поверхности образца внутри последнего формировалась область растяжения, и при достижении растягивающих напряжений, критических для нагружаемого материала значений, происходило внутреннее разрушение (расслоение) образца, так называемое откольное разрушение. В процессе ударно-волнового нагружения тестируемых образцов во всех экспериментах осуществлялась непрерывная регистрация скорости движения их свободной тыльной поверхности $u_{f s}(t)$ с помощью лазерного допплеровского измерителя скорости VISAR (Velocity Interferometric System for Any Reflection) [22] c разрешением $\sim 1 \mathrm{~ns}$ по времени и $\pm 3 \mathrm{~m} / \mathrm{s}$ по величине измеряемой скорости.

Скорость деформирования вещества перед разрушением в данных условиях есть скорость расшире- ния вещества в волне разрежения, определяемая как $\dot{V} / V_{0}=-\dot{u}_{f s r} / 2 c_{b}$, где $\dot{u}_{f s r}-$ измеренный градиент скорости свободной поверхности испытуемого образца в разгрузочной части импульса ударного сжатия, $c_{b}$ - объемная скорость звука, измеренная для образцов СПУМЭ ультразвуковым методом равной $1750 \mathrm{~m} / \mathrm{s}$. Добавки УНЧ практически не влияли на ее величину. При анализе экспериментальных данных использовалась ударная адиабата полиуретана без учета добавок УНЧ ввиду их малости в виде линейного соотношения между скоростью ударной волны $U_{\mathrm{s}}$ и массовой скоростью $u_{p}$ : $U_{s}=2073+2043 u_{p}(\mathrm{~m} / \mathrm{s})[23]$.

\section{2. Результаты и их обсуждение}

\section{1. Результаты статических измерений}

Введение УНЧ в полимер можно осуществлять различными способами [13], при этом наиболее часто используемыми являются введение в расплав или раствор готового полимера и in-situ полимеризация, когда наночастицы добавляют в исходную реакционную смесь. Для сшитых полимеров, к которым относится объект данного исследования СПУМЭ, в силу их нерастворимости и неплавкости, возможен только in-situ метод. Довольно часто УНЧ при этом способе введения добавляют в виде дисперсии в различных растворителях, в нашем случае это толуол, который, как описано в экспериментальной части, удаляли вакуумированием при перемешивании и нагреве реакционной смеси. В тестовых экспериментах в настоящей работе было исследовано также влияние добавленного и затем удаленного растворителя на физикомеханические характеристики СПУМЭ. Было установлено, что полимер, подвергнутый операции введения и удаления растворителя, меняет свои характеристики по сравнению со СПУМЭ, полученным в аналогичных условиях, но в отсутствие толуола. Начальный модуль упругости Юнга возрастает на $27 \%$ с 5.7 до $7.2 \mathrm{MPa}$, а предел прочности при растяжении и относительное удлинение при разрыве меняются незначительно, но также с тенденцией к возрастанию (с 12 до $12.2 \mathrm{MPa} \mathrm{и}$ с 1780 до $1820 \%$ соответственно). Наблюдаемое упрочнение полимера можно объяснить с большой долей вероятности протеканием побочной реакции мочевинообразования за счет наличия влаги в растворителе. Полученные результаты были учтены в ходе дальнейшей работы путем нормирования значений физикомеханических параметров образцов нанокомпозитов к значениям таковых для образца СПУМЭ, синтезированного в тестовом эксперименте. Следует отметить, что в литературе не встречается описание подобных исследований по влиянию растворителей на свойства полимеров при введении в их состав наночастиц в виде дисперсии, что может сказываться на корректности получаемых экспериментальных результатов.

В качестве первого этапа исследования синергетического эффекта при введении в СПУМЭ сочетаний 


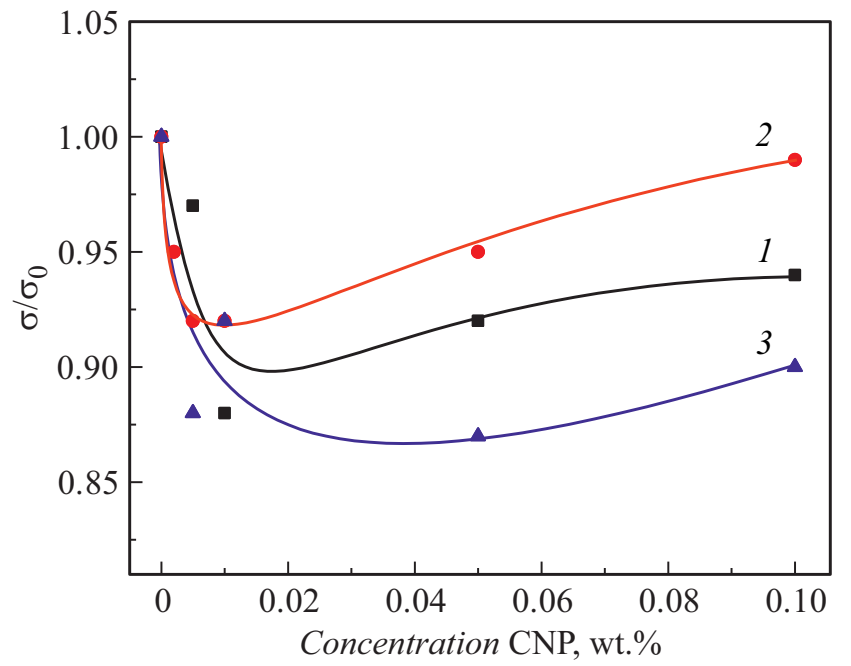

Рис. 1. Зависимость изменения относительного предела прочности на разрыв нанокомпозитов от концентрации УНЧ: 1 фуллерен, $2-$ ОГ, $3-$ смесь ОГ и фуллерена в соотношении $15 / 85$.

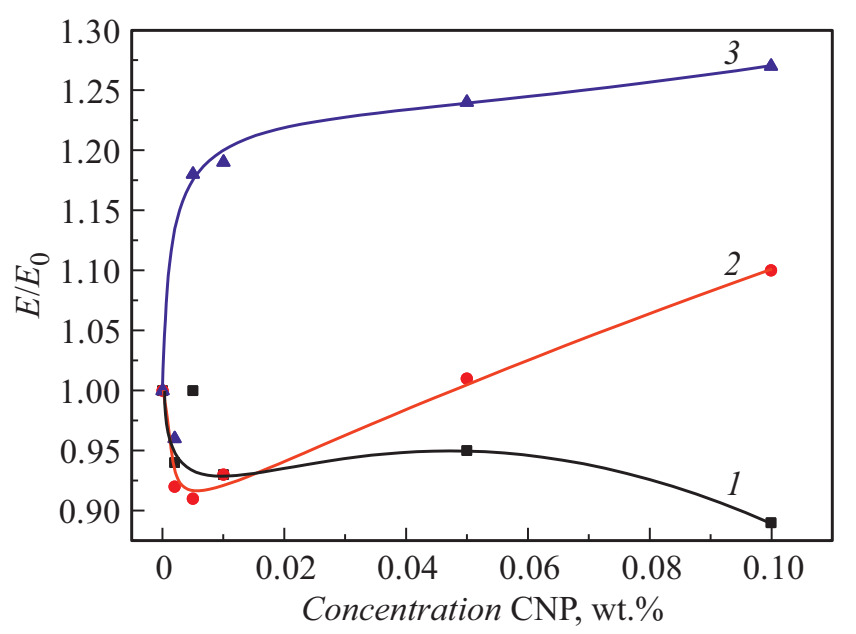

Рис. 2. Зависимость изменения относительного модуля упругости нанокомпозитов от концентрации УНЧ: 1 - фуллерен, 2 - ОГ, 3 - смесь ОГ и фуллерена в соотношении 15/85.

УНЧ было изучено влияние добавок индивидуальных наночастиц - ОГ и фуллерена, а затем их смеси в соотношении ОГ/фуллерен, равным $15 / 85$, на физикомеханические свойства образующихся нанокомпозитов (рис. 1-3). Здесь и далее СПУМЭ - это образец, синтезированный в тестовом эксперименте.

Анализ результатов свидетельствует, что наночастицы как в индивидуальном виде, так и в виде смеси весьма неоднозначно влияют на начальный модуль упругости, предел прочности при растяжении и относительное удлинение при разрыве. На рис. 1 представлены зависимости изменения относительного предела прочности $\sigma / \sigma_{0}$ от концентрации УНЧ. Здесь $\sigma-$ значение предела прочности при растяжении нанокомпозита при определенной концентрации УНЧ, $\sigma_{0}$ - значение преде- ла прочности при растяжении СПУМЭ, полученного в тестовом эксперименте. Как видно из рисунка, во всех случаях наблюдается примерно одинаковый ход этих зависимостей. А именно, после некоторого снижения прочности при введении сверхмалых количеств наночастиц ( до $5-10 \times 10^{-3}$ wt.\%) можно видеть ее незначительный рост с увеличением количества введенных УНЧ. При этом только в случае ОГ (при концентрации $0.1 \mathrm{wt. \%}$ ) предел прочности при растяжении достигает значений, продемонстрированных образцом СПУМЭ в тестовом эксперименте (рис. 1, кривая 2). Отметим, что в случае смеси фуллерен-ОГ проявился некоторый синергетический эффект их отрицательного влияния на предел прочности нанокомпозита (рис. 1, кривая 3).

Иной характер наблюдается для зависимостей изменения относительного начального модуля упругости $E / E_{0}$ от концентрации УНЧ (рис. 2). В случае добавок фуллерена (рис. 2, кривая I) модуль упругости нанокомпозита в целом имеет тенденцию к снижению, и при максимально исследованной концентрации 0.1 mass.\% значения его примерно на $10 \%$ ниже, чем у ненаполненного образца. Введение ОГ в полиуретан приводит к инверсии вышеописанной зависимости и соответственно повышению примерно на те же $10 \%$ значений модуля Юнга по сравнению с исходным образцом СПУМЭ при содержании наночастиц 0.1 mass.\% (рис. 2, кривая 2). Использование в качестве добавки сочетания ОГ-фуллерен демонстрирует явный синергетический эффект (рис. 2, кривая 3), приводя к 20\%-ому превышению модуля упругости относительно ненаполненного образца уже при общей концентрации ОГ+фуллерен 0.01 wt.\% и к 30\%-ому - при 0.1 wt.\%.

Зависимости относительного удлинения при разрыве $\varepsilon / \varepsilon_{0}$ от концентрации УНЧ (рис. 3), как и следовало ожидать, в целом антибатны зависимостям начального модуля упругости, за исключением нанокомпозита СПУМЭ-фуллерен.

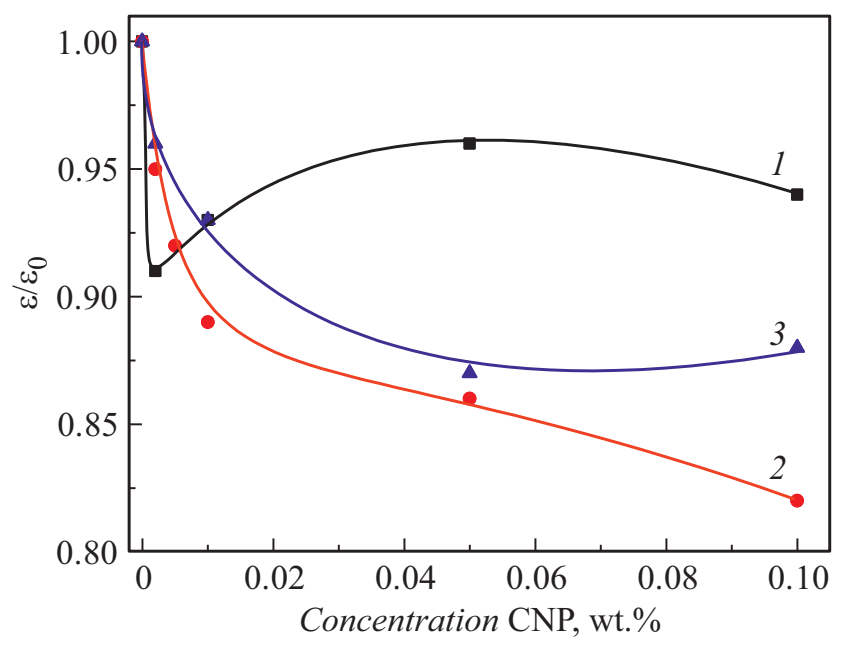

Рис. 3. Зависимость относительного удлинения при разрыве нанокомпозитов от концентрации УНЧ: $1-$ фуллерен, $2-$ ОГ, 3 - смесь ОГ и фуллерена в соотношении $15 / 85$. 
Наблюдаемые изменения модуля связаны, очевидно, с изменением структуры полимера при введении в них УНЧ. Так, снижение модуля упругости нанокомпозита СПУМЭ-фуллерен объясняется, по-видимому, тем, что молекулы фуллерена способны, в какой-то мере, препятствовать образованию связей, формирующих физическую сетку полимерной матрицы. В присутствии ОГ на структуру СПУМЭ возможно влияние двух конкурирующих факторов - с одной стороны, как и в случае фуллерена, препятствие образованию связей физической сетки, с другой - формирование дополнительных ковалентных связей за счет большого количества функциональных групп на поверхности ОГ, способных взаимодействовать с реагентами в ходе синтеза нанокомпозита. Можно предположить, что первый фактор превалирует при сверхмалых концентрациях ОГ, второй - начинает играть ощутимую роль при концентрациях ОГ выше $\sim 0.05 \mathrm{wt} . \%$, как это следует из экспериментальных данных. Синергетический эффект при совместном присутствии ОГ и фуллерена связан, повидимому, с тем, что уже на стадии диспергирования фуллерен проникает в межслоевое пространство ОГ, и при введении таких наноструктур в реакционную смесь в большей степени реализуется потенциал ОГ в формировании дополнительных ковалентных связей.

Изменение структуры СПУМЭ в присутствии наибольшей из исследованных концентраций (0.1 wt.\%) добавок наночастиц проявляется и при анализе образцов методом рентгеновской дифракции в малых углах (рис. 4).

На кривых присутствует интенсивный малоугловой пик в диапазоне $q=0.2-1.5 \mathrm{~nm}^{1}$, соответствующий наличию в матрице фазово-разделенной морфологии с характерным расстоянием между доменами $7.18 \mathrm{~nm}$ (рис. 4,a). Важно отметить, что положение этого пика не зависит от концентрации и состава нанонаполнителя. Можно предположить, что он соответствует рассеянию на кристаллитах полиамидных блоков, образующихся, как отмечено в экспериментальной части, в результате полимеризации блокирующего агента $\varepsilon$-капролактама. Второй менее выраженный пик наблюдается в районе $2-4 \mathrm{~nm}^{-1}$ и соответствует третьему дифракционному порядку основного пика $(2.37 \mathrm{~nm})$. Однако интенсивность и положение пика в данной области сильно меняется с типом нанонаполнителя (рис. 4, $b$ ). Так, на кривых инварианта, нормированных на интенсивность основного пика, четко видно увеличение относительной интенсивности данного пика по сравнению с первым дифракционным порядком при введении наночастиц. Поскольку основная частично кристаллическая морфология полимерной матрицы в серии образцов не меняется, данный рост, по-видимому, связан с присутствием дополнительного сигнала от нанонаполнителя. Это подтверждается смещением центра масс пика к $q=3.1 \mathrm{~nm}^{-1}$ для образца, содержащего только фуллерен и к $q=2.7 \mathrm{~nm}^{-1}$ для образца, содержащего только ОГ. Для образца, содержащего смесь фуллерен-ОГ, центр
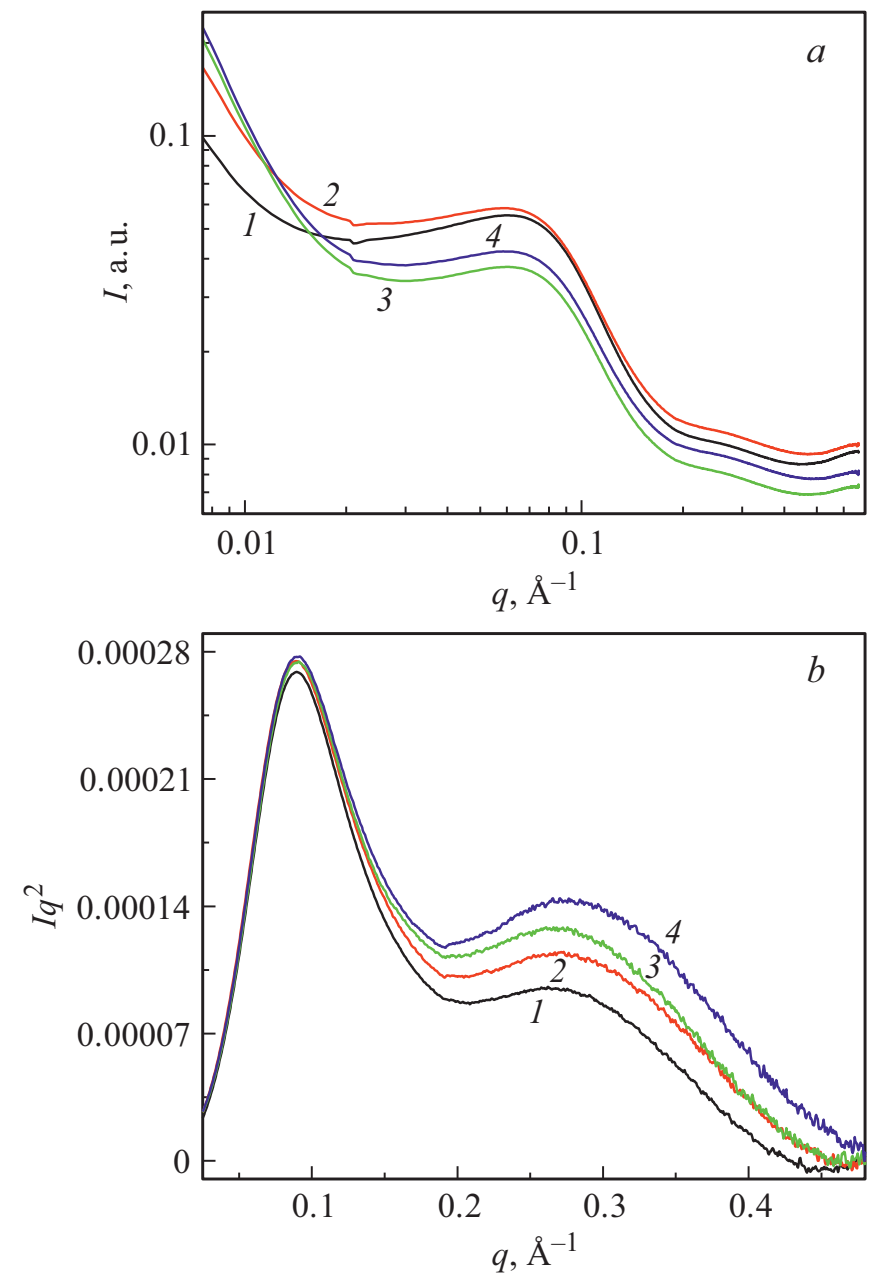

Рис. 4. Кривые малоуглового рассеяния $(a)$ и инварианты рассеяния $(b)$ СПУМЭ и нанокомпозитов на его основе: 1 - СПУМЭ, 2 - СПУМЭ+фуллерен, 3 - СПУМЭ+ОГ, 4 - СПУМЭ+смесь ОГ и фуллерена в соотношении 15/85.

масс расположен при $q=2.9 \mathrm{~nm}^{-1}$, что указывает на то, что вклад рассеяния от ОГ в данный пик значительно выше.

О различиях в размерах агрегатов наночастиц можно судить по наклону кривых в малоугловых областях $\left(q<0.2 \mathrm{~nm}^{-1}\right)[24]$. Видно, что при наличии фуллерена в СПУМЭ наклон резко увеличивается по сравнению с исходной матрицей (рис. 4,a), что связано с образованием агрегатов наночастиц размером более $50 \mathrm{~nm}$. Введение ОГ дает еще больший наклон кривой, что указывает на формирование более крупных агрегатов, происходящее в силу существенно больших размеров ОГ по сравнению с фуллереном (примерно 3-5 $\mu$ и и $0.7 \mathrm{~nm}$ соответственно). Для композита, содержащего смесь фуллерен-ОГ, наклон кривой соответствует рассеянию от агрегатов ОГ, хотя его содержание в смеси составляет всего $15 \%$, что можно объяснить формированием более крупных наноструктур за счет проникновения фуллерена в межслоевое пространство ОГ. 


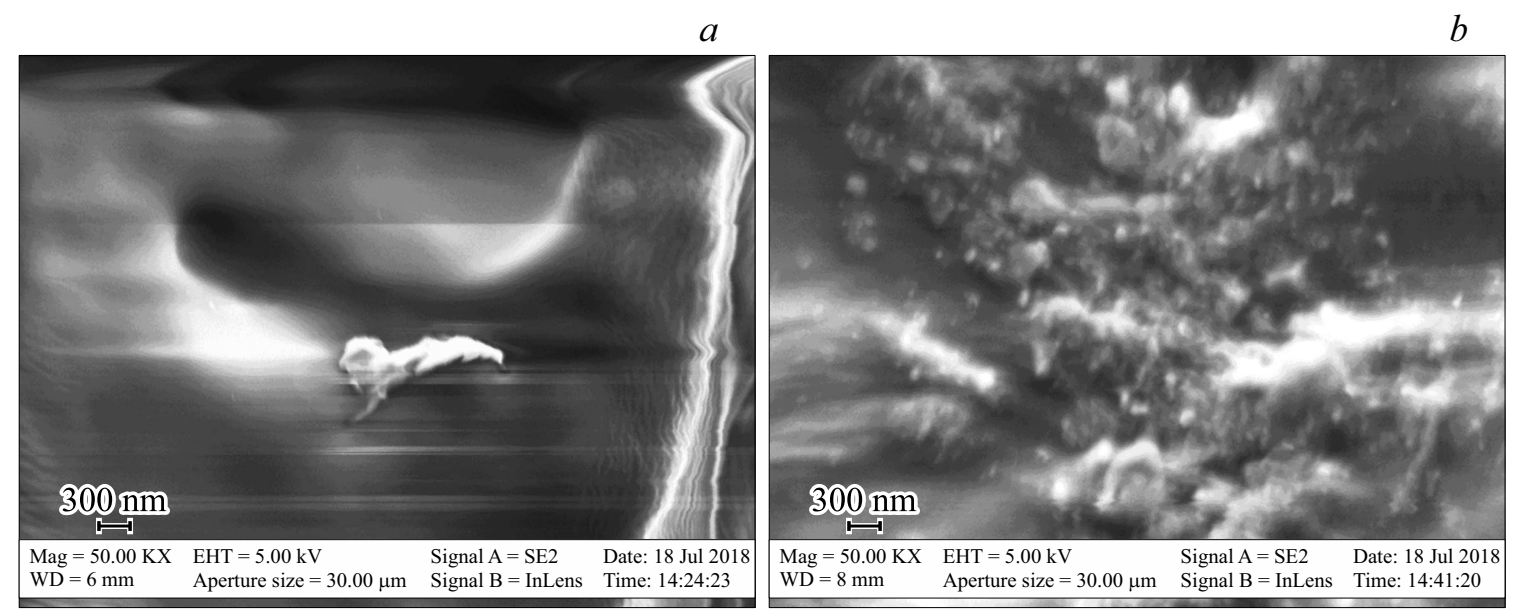

$c$

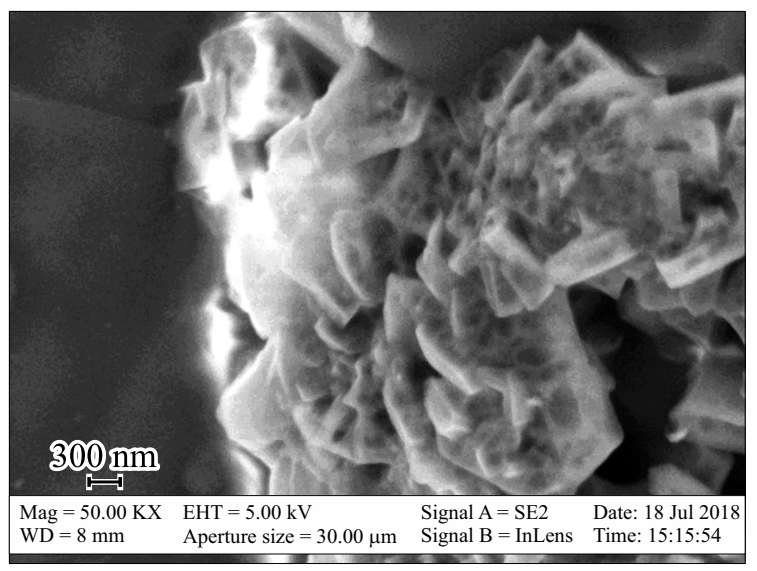

Рис. 5. Микрофотографии образцов нанокомпозитов на основе СПУМЭ и фуллерена $(a)$, ОГ $(b)$ и смеси ОГ-фуллерен в соотношении 15:85 (c). Концентрация УНЧ $0.1 \mathrm{wt} \%$. Масштаб $300 \mathrm{~nm}$.

Данные о размере агрегатов наночастиц в матрице СПУМЭ, полученные методом рентгеноструктурного анализа, подтверждаются результатами микроскопического анализа образцов (рис. 5).

Видно, что наиболее крупные агрегаты формируются в нанокомпозите, содержащем смесь наночастиц ОГ и фуллерена, при этом благодаря вероятному взаимопроникновению наночастиц различной морфологии указанные агрегаты более рыхлые. Это, по-видимому, облегчает взаимодействие функциональных групп ОГ с реагентами при формировании дополнительных ковалентных связей, приводя, как отмечено выше, к наблюдаемому синергетическому эффекту увеличения модуля упругости. (Мелкие частицы, присутствующие на фотографиях, представляют собой, скорее всего, осколки полимера, образовавшиеся при разрушении образца, замороженного в жидком азоте, в процессе подготовки полимера к анализу).

Следует отметить, что вышеописанные наблюдаемые изменения свойств и структуры СПУМЭ в присутствии УНЧ практически не отразились на температуре стеклования образцов, определенной методом динамического механического анализа из зависимости тангенса угла механических потерь от температуры при постоянной частоте в $1 \mathrm{~Hz}$ (во всех случаях она составляла $\left.-38.7^{\circ} \mathrm{C} \pm 0.3\right)$.

\section{2. Результаты ударно-волновых экспериментов}

Помимо исследования совместного влияния фуллерена и ОГ на физико-механические свойства СПУМЭ в статических условиях были выполнены эксперименты по высокоскоростному деформированию динамическому (ударно-волновому) нагружению этих образцов с целью измерения их динамической (откольной) прочности при скорости деформирования $\sim 10^{5} \mathrm{~s}^{-1}$. Проведенные в настоящей работе динамические измерения основаны на том, что эволюция (формоизменение) ударной волны при распространении вглубь образца отражает все релаксационные процессы, протекающие внутри нагруженного материала. Анализ полных волновых профилей $u_{f s}(t)$ позволяет получать не только качественную информацию о протекающих в материале процесcax, связанных с ударно-волновым нагружением, но и рассчитать количественные характеристики параметров 


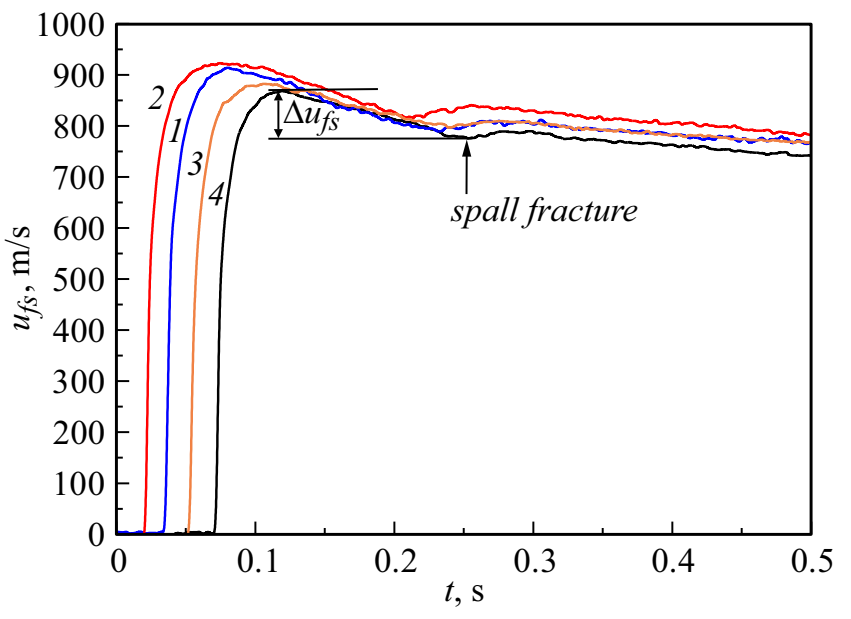

Рис. 6. Профили скорости свободной поверхности СПУМЭ и нанокомпозитов на его основе, зарегистрированные в ударно-волновых экспериментах: 1 - СПУМЭ, 2 СПУМЭ+фуллерен, 3 - СПУМЭ+ОГ, 4 - СПУМЭ+смесь ОГ и фуллерена в соотношении 15/85. Концентрация УНЧ $0.1 \mathrm{wt} . \%$.

ударных волн сжатия и прочностные характеристики исследуемого материала.

Профили скорости свободной поверхности образцов СПУМЭ в отсутствие и в присутствии УНЧ различной морфологии, измеренные в процессе их ударноволнового нагружения, представлены на рис. 6. Видно, что все волновые профили подобны независимо от состава СПУМЭ. Для лучшей наглядности они сдвинуты относительно друг друга. На поверхность образца выходит пластическая волна сжатия амплитудой до $1.5 \mathrm{GPa}$, ускоряя ее до скорости выше $800 \mathrm{~m} / \mathrm{s}$. Время нарастания параметров во фронте ударной волны во всех экспериментах не превышает $10 \mathrm{~ns}$. В отличие от многих конструкционных материалов, в том числе и полимерных, полиуретан не проявляет упругопластических свойств [25], т.е. при ударном сжатии СПУМЭ практически сразу начинает деформироваться пластическим образом, и формирование упругого предвестника, связанного с деформированием материала в упругой области, не наблюдается. Сразу за пластической волной сжатия на поверхность образца выходит волна разрежения, в которой скорость поверхности уменьшается. Длительность импульса сжатия в таких экспериментах определяется временем реверберации волн в ударнике. В этих опытах соотношение толщины образца и толщины ударника было примерно $1: 5$, что приводило к формированию на свободной поверхности образцов импульса сжатия треугольной формы, т.е. после ударного сжатия вещество практически сразу начинало разгружаться в волне разгрузки. После отражения импульса сжатия от свободной поверхности образца внутри него в результате интерференции падающей и отраженной волн разрежения генерируются растягивающие напряжения, при достижении критических значений которых инициируется его разрушение - откол (момент откольного разрушения обозначен стрелкой на рис. 6). При формировании откольной трещины (расслаивании образца) происходит релаксация растягивающих напряжений, и формируется волна сжатия - откольный импульс, выход которого на поверхность образца вызывает второй подъем ее скорости. В отличие от аналогичных экспериментов с нанокомпозитами на основе отвержденных эпоксидных смол с малыми добавками УНТ [26] в случае нанокомпозитов на основе СПУМЭ, как это видно на профилях скорости, откольный импульс достаточно слабый и растянут по времени, что означает затянутое по времени формирование области разрушения в объеме образца. Дальнейшие реверберации откольного импульса в откольной пластине обычно приводят к затухающим осцилляциям скорости свободной поверхности. В экспериментах с образцами СПУМЭ такие осцилляции практически отсутствуют в силу быстрого затухания откольного импульса на поверхности разрушения.

Как следует из анализа методом характеристик, величина растягивающих напряжений непосредственно перед откольным разрушением, называемая откольной прочностью материала, пропорциональна величине декремента скорости свободной поверхности $\Delta u_{f s}$ от ее максимального значения до значения непосредственно перед фронтом откольного импульса (рис. 6). В линейном (акустическом) приближении величина откольной прочности $\sigma_{s p}$ рассчитывается как $\sigma_{s p}=1 / 2 \rho_{0} c_{b}\left(\Delta u_{f s}\right), \rho_{0}-$ исходная плотность полимера, $c_{b}$ - объемная скорость звука, $\Delta u_{f s}$ - спад скорости от максимума до первого минимума в момент разрушения (рис. 6) [21].

Наибольшей прочностью на растяжение $127 \mathrm{MPa} \mathrm{при}$ отколе обладают образцы исходного СПУМЭ. Малые добавки фуллерена или ОГ заметно снижают сопротивление этих композитных полиуретановых образцов откольному разрушению - более чем на 15 и 30\% соответственно. При введении в СПУМЭ смеси фуллеренОГ значение критического разрушающего напряжения $\sim 93 \mathrm{MPa}$. Такую реакцию исследованных нанокомпозитов на ударно-волновой отклик можно объяснить следующим. СПУМЭ характеризуется в целом однородной структурой, и разрушение инициируется на существующих внутренних дефектах этой структуры. Добавка же в объем полимера твердых по сравнению с веществом матрицы частиц создает в объеме полимера многочисленные дополнительные очаги разрушения, которое и развивается при меньших растягивающих напряжениях. Суммарный эффект этих частиц практически не меняет реакцию композита на растяжение, т.е. в данном случае определяющими в процессе откольного разрушения являются частицы ОГ.

\section{Заключение}

В работе представлены впервые проведенные исследования, сочетающие изучение структуры, физикомеханических свойств при статических и динамических нагрузках сшитых полиуретанов, содержащих малые и 
сверхмалые добавки фуллерена, ОГ и их смеси. Установлено, что синергетический эффект совместного влияния ОГ и фуллерена проявляется в увеличении модуля упругости нанокомпозита, полученного в присутствии указанной смеси в соотношении 15/85. В то же время УНЧ как в индивидуальном состоянии, так и в виде их сочетания снижают прочность композита и при статических нагрузках, и при ударно-волновом нагружении.

Рост модуля упругости может быть связан с формированием дополнительной сетки химических связей при введении УНЧ, имеющих модуль упругости, намного превышающий модуль упругости полимерной матрицы, за счет наличия функциональных групп в ОГ. В случае сочетания наночастиц различной морфологии уже на стадии диспергирования фуллерен, по всей вероятности, проникает в межслоевое пространство ОГ с образованием более рыхлых структур, что подтверждается данными РСА и СЭМ. При введении таких наноструктур в реакционную смесь в большей степени реализуется потенциал ОГ в формировании дополнительных ковалентных связей, что обусловливает наблюдаемый синергетический эффект. В свою очередь, прочностные характеристики нанокомпозитов зависят от внутренней дефектной структуры материала. При добавлении в полимерную мягкую матрицу жестких наноуглеродных частиц в объеме матрицы формируется поле дополнительных дефектов, на которых инициируется разрушение независимо от скорости деформирования.

\section{Финансирование работы}

Работа выполнена по темам государственного задания, №№ гос. регистрации 01201361852, 01201361856, 012001361856 и 01201055328 и при финансовой поддержке Программ Президиума РАН №№ 13П и 32П и проекта Министерства образования и науки РФ № 14.578.21.0190, идентификатор RFMEFI57816X0190

\section{Список литературы}

[1] Yang S.-Y., Lin W.-N., Huang Y.-L., Tien H.-W., Wang J.-Y., Ma C.-C. M., Li S.-M., Wang Y.-S. // Carbon. 2011. Vol. 49. N 3. P. 793-803. DOI: 10.1016/j.carbon.2010.10.014

[2] Yu A., Ramesh P., Sun X., Bekyarova E., Itkis M.E., Haddon R.C. // Adv. Mater. 2008. Vol. 20. N 24. P. 47404744.

DOI: $10.1002 /$ adma.200800401

[3] Shin M.K., Lee B., Kim S.H., Lee J.A., Spinks G.M., Gambhir S., Wallace G.G., Kozlov M.E., Baughman R.H., Kim S.J. // Nat. Commun. 2012. Vol. 3. N 1. P. 650. DOI: $10.1038 /$ ncomms1661 (2012)

[4] Xu P., Loomis J., King B., Panchapakesan B. // Nanotechnology. 2012. Vol. 23. N 31. P. 315706. DOI: $10.1088 / 0957-4484 / 23 / 31 / 315706$

[5] Prasad K.E., Das B., Maitra U., Ramamurty U., Rao C.N. // Proc. Natl. Acad. Sci. 2009. Vol. 106. N 32. P. 13186-13189. DOI: $10.1073 /$ pnas.0905844106

[6] Feng Y., Qin M., Guo H., Yoshino K., Feng W. // ACS Appl. Mater. Interfaces. 2013. Vol. 5. N 21. P. 10882-10888. DOI: $10.1021 / \mathrm{am} 403071 \mathrm{k}$
[7] Yue L., Pircheraghi G., Monemian S.A., Manas-Zloczower I. // Carbon N.Y. 2014. Vol. 78. P. 268-278. DOI: 10.1016/j.carbon.2014.07.003

[8] Li Y., Yang T., Yu T., Zheng L., Liao K. // J. Mater. Chem. 2011. Vol. 21. N 29. P. 10844-10851. DOI: $10.1039 / \mathrm{c} 1 \mathrm{jm} 11359 \mathrm{c}$

[9] Ponnamma D., Sadasivuni K.K., Strankowski M., Guo Q., Thomas S. // Soft Matter. 2013. Vol. 9. N 43. P. 10343. DOI: $10.1039 / \mathrm{C} 3 \mathrm{SM} 51978 \mathrm{C}$

[10] Jin S., Li K., Li J. // Polymers. 2018. Vol. 10. N 3. P. 270. DOI: $10.3390 /$ polym 10030270

[11] Wang P.-N., Hsieh T.-H., Chiang C.-L., Shen M.-Y. // J. Nanomater. 2015. Vol. 2015. P. 1-9. DOI: $10.1155 / 2015 / 838032$

[12] Yuan D., Pedrazzoli D., Manas-Zloczower I. // Int. Polym. Process. 2016. Vol. 31. N 5. P. 554-561. DOI: $10.3139 / 217.3231$

[13] Badamshina E., Estrin Y., Gafurova M. // J. Mater. Chem. A. 2013. Vol. 1. N 22. P. 6509. DOI: 10.1039/C3TA10204A

[14] Tayfun U., Kanbur Y., Abaci U., Guney H.Y., Bayramli E. // Compos. Part B Eng. 2015. Vol. 80. P. 101-107. DOI: $10.1016 /$ j.compositesb.2015.05.013

[15] Huang W., Li Z., Chen X., Tian P., Lu J., Zhou Z., Huang R., Hui D., He L., Zhang C., Wang X. // Compos. Part B Eng. 2014. Vol. 62. P. 126-136.

DOI: $10.1016 /$ j.compositesb.2014.02.026

[16] Avilés F., May-Pat A., López-Manchado M.A., Verdejo R., Bachmatiuk A., Rümmeli M.H. // Eur. Polym. J. 2018. Vol. 99. P. 394-402.DOI: 10.1016/j.eurpolymj.2017.12.038

[17] Heydari A., Sheibani H., Hronský V., Janigová I., Šlouf M., Šiffalovič P., Chodák I. // Chem. Pap. 2018. Vol. 72. N 5. P. 1299-1313. DOI: 10.1007/s11696-017-0371-9

[18] Kumar A., Rao K.M., Han S.S. // Carbohydr. Polym. 2018. Vol. 193. P. 228-238. DOI: 10.1016/j.carbpol.2018.04.004

[19] Estrin Ya.I., Badamshina E.R., Grishchuk A.A., Kulagina G.S., Lesnichaya V.A., Ol'khov Yu.A., Ryabenko A.G., Sul'yanov S.N. // Polymer Sci. Series A. 2012. Vol. 54. N 4. P. 290-298. DOI: 10.1134/S0965545X12040037 [Estrin Ya.I., Badamshina E.R., Grishchuk A.A., Kulagina G.S., Lesnichaya V.A., Ol'khov Yu.A., Ryabenko A.G., Sulyanov S.N. // Published in Vysokomolekulyarnye Soedineniyaю Ser. A. 2012. Vol. 54. N 4. P. 568-577.]

[20] Shulga Y.M., Baskakov S.A., Smirnov V.A., Shulga N.Y., Belay K.G., Gutsev G.L. // J. Power Sources. 2014. Vol. 245. P. 33-36. DOI: 10.1016/j.jpowsour.2013.06.094

[21] Antoun T., Seaman L., Curran D.R., Kanel G.I., Razorenov S.V., Utkin A.V. Spall Fracture. NY.: SpringerVerlag, 2003. $404 \mathrm{p}$.

[22] Barker L.M., Hollenbach R.E. // JAP. 1972. Vol. 43. N 11. P. 4669. DOI: 10.1063/1.1660986

[23] LASL shock Hugoniot data / ed. Marsh S.P. Berkeley: University of California Press, 1980. $658 \mathrm{p}$.

[24] Zhu X., Melian C., Dou Q., Peter K., Demco D.E., Möller M., Anokhin D.V., Le Meins J.-M., Ivanov D.A. // Macromolecules. 2010. Vol. 43. N 14. P. 6067-6074. DOI: 10.1021/ma1007573

[25] Kanel G.I., Fortov V.E., Razorenov S.V. Shock-Wave Phenomena and the Properties of Condensed Matter. NY: Springer, 2004. $321 \mathrm{p}$.

[26] Тарасов А.Е., Бадамшина Э.Р., Анохин Д.В., Разоренов С.В., Вакорина Г.С. // ЖТФ. 2018. Т. 88 Вып. 1. C. 34-41. DOI: 10.21883/JTF.2018.01.45478.2354 [Tarasov A.E., Badamshina E.R., Anokhin D.V., Razorenov S.V., Vakorina G.S. // Tech. Phys. 2018. Vol. 63. N 1. P. 32-40.] 